Aletria, Belo Horizonte, v. 28, n. 4, p. 65-85, 2018

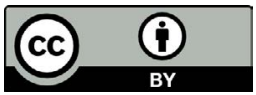

\title{
Representando a resistência negra no Brasil: originalidade e limites de Um defeito de cor, de Ana Maria Gonçalves
}

\section{Representing Black Resistance in Brazil: Originality and Limits of Um defeito de cor, by Ana Maria Gonçalves}

\author{
Gabriel Estides Delgado \\ Universidade de Brasília (UnB), Brasília, Distrito Federal / Brasil \\ Capes \\ gabrielestides@gmail.com
}

Resumo: Com uma poética calcada no transplante cultural africano, Ana Maria Gonçalves leva a cabo, em Um defeito de cor, a tarefa titânica de recontagem da resistência negra no país a partir de um ponto de vista feminino e negro. No relato de uma narradora octogenária, ex-escrava de nação jeje, o fôlego monumental do romance perfaz aprofundada vivência de culturas originárias, incorporando léxicos de etnias traficadas e ritualísticas totêmicas, em tentativa de representação da importância de tal legado para a integração negra no Brasil. Sustentamos que a originalidade daí desprendida é capaz de contraditar um dos marcos da sociologia crítica brasileira: a tese $A$ integração do negro na sociedade de classes, de Florestan Fernandes. Essa complementação fundamental a historiografias consagradas sobre as populações afro-brasileiras depende das possibilidades do registro ficcional, as quais, no entanto, ficam obstadas por escolhas formais conservadoras, que limitam, sem anular, a potência literária da obra.

Palavras-chave: Um defeito de cor; Ana Maria Gonçalves; literatura afro-brasileira contemporânea; resistência cultural; representação.

Abstract: With a poetics based on African cultural transplant, Ana Maria Gonçalves carries out in Um defeito de cor the titanic task of recounting Brazilian black resistance from a feminine and black point of view. In the report of a former octogenarian Jeje nation slave, the monumental breath of the novel fulfills a thorough experience of 
native cultures, incorporating lexicons of trafficked ethnic groups and totemic rituals, in an attempt to represent the importance of such a legacy for black integration in Brazil. The originality that emerges therefrom is capable of contradicting one of the Brazilian critical sociology milestones, the thesis $A$ integração do negro na sociedade de classes, by Florestan Fernandes. This fundamental complementation to consecrated historiographies on Afro-Brazilian populations depends on the possibilities of the fictional record, which, however, are obstructed by conservative formal choices that limit, without annulling it, the literary power of the work.

Keywords: Um defeito de cor; Ana Maria Gonçalves; Afro-Brazilian contemporary literature; cultural resistance; representation.

Um defeito de cor, romance de 2006 escrito por Ana Maria Gonçalves, tornou-se uma referência da literatura negra brasileira neste começo de século. A visada interna e feminina, conjugada ao fôlego narrativo épico que conforma a representação da experiência afro-brasileira antes e após a Abolição da escravatura, parece reservar a posição de livro incontornável na produção literária brasileira contemporânea. Não obstante a consagração, que se ampara na relativa novidade da empresa quando contraposta à ficção nacional corrente, resta um necessário retorno ao texto da autora de origem mineira para que possamos destrinchar as características de tal originalidade.

Gonçalves depositará sobre a construção da narradora de Um defeito de cor - uma personagem histórica do século XIX - anseios característicos do ponto de vista autoral feminino e negro que representa. A reação poética profusa da obra é tanto à realidade brasileira como um todo - e, não por acaso, o gênero assumido na empresa é o romance histórico, gênero de recuperação histórica - quanto a um campo literário com carência de referências negras. ${ }^{1} \mathrm{O}$ fôlego épico demora-se sobre

\footnotetext{
${ }^{1}$ Cf. DALCASTAGNÈ. Um mapa de ausências. As pesquisas de Regina Dalcastagnè, reunidas no livro Literatura brasileira contemporânea: um território contestado, têm demonstrado não só a homogeneidade do perfil autoral brasileiro publicado pelas grandes e prestigiosas editoras locais. Masculino e branco, tal perfil - aferido quantitativamente (DALCASTAGNÈ. Um mapa de ausências, p. 162) - prolonga-se no espaço composicional das obras, determinando a matéria ficcional e a maneira de formalizá-la. O que se tem de modo majoritário são dramas pequeno-burgueses narrados
} 
experiências suprimidas pela narrativa hegemônica eurocêntrica; o protagonismo narrativo africano, o resgate de sua ancestralidade diversa - imune, parcialmente, às investidas do sequestro, tráfico e espoliação -, revelam grande força literária, abrindo caminhos mais largos do que poéticas pautadas sobre o fragmento escritural.

Veremos que tal ficcionalização da história é capaz de sedimentar determinado repertório simbólico e material ausente tanto das narrativas historiográficas hegemônicas quanto da sociologia crítica brasileira. Nesse sentido, sem negar a diferença entre o registro sociológico e o literário, cotejaremos o romance de Gonçalves com a tese $A$ integração do negro na sociedade de classes (1964), de Florestan Fernandes. Na pesquisa do sociólogo paulistano, ainda que se ressalte a capacidade de agência das populações negras - em recorte temporal em parte coincidente com $U m$ defeito de cor -, o foco recai, de modo majoritário, sobre a inadequação de seu aparato de técnicas sociais em relação à incipiente sociedade competitiva (do final do século XIX em diante). A anomia é herdada do cativeiro e não há "laços de interdependência, responsabilidade e de solidariedade" que integrem "fortemente os homens, nos pequenos ou nos grandes agrupamentos sociais". ${ }^{2} \mathrm{O}$ fatalismo daí desprendido, embora tratando-se de um dos primeiros grandes estudos a denunciar o "mito da democracia racial", recebe, como tentaremos demonstrar, complemento fundamental na ficção de Gonçalves. A contradita representada por $U m$ defeito de cor, entretanto, não alcança maior potência porque, malgrado a história de excepcionalidade que ergue derivar dos firmes laços culturais cultivados pelas populações afro-brasileiras, seu esforço de figuração e formalização - uma reescrita literária da história - permanece tímido, como que refém do ímpeto reparatório e de sua responsabilidade política.

\section{A narrativa de Kehinde}

Kehinde narra sua saga desde um navio, em 1899, quando tentará sua última chegada ao Brasil, já cega e com cerca de 89 anos. ${ }^{3}$ Da viagem, que talvez não se complete para a protagonista (há uma indeterminação

\footnotetext{
e protagonizados por personagens que replicam o perfil autoral, numa sensaboria autorreferente típica da ausência de diversidade.

${ }^{2}$ FERNANDES. A integração do negro na sociedade de classes, v. 1, p. 76.

${ }^{3}$ GONÇALVES. Um defeito de cor, p. 911, 931-933.
} 
do enredo nesse sentido), restarão manuscritos redigidos por Geninha, companheira de travessia daquela que à época transformara-se em grande senhora daomeana. A emancipação excepcional da outrora escrava brasileira - que volta a sua nação africana, o reino de Daomé, o Benim contemporâneo, e acaba por enriquecer, também sobre território nigeriano, como empreiteira de casas e bairros em estilo ocidental -, nutre-se das inflexões da épica. O ponto de chegada absolutamente insuspeito é construído pormenorizadamente, em transcurso narrativo contíguo à construção do Brasil moderno. É que na vida de titã que acompanharemos, Kehinde alude historicamente a Luíza Mahin, "mito libertário do feminismo negro"4, tida por articuladora e partícipe da Revolta dos Malês (1835) em Salvador, e mãe de Luiz Gama (1830-1882).

Apesar de ser reverenciada muitas vezes como personagem histórica (real) pelo movimento negro brasileiro, ${ }^{5}$ o primeiro documento que descreve a heroína é uma carta autobiográfica de Luiz Gama. Vendido pelo pai branco como escravo ainda muito menino - tinha então 10 anos -, Gama confere à figura materna, na epístola, uma conformação lendária, de impossível comprovação, como já indicado por diversos estudos. ${ }^{6} \mathrm{De}$ 1880 - data da carta - em diante, o imaginário sobre a mãe de Gama vem sendo alimentado na trilha do ímpeto insurrecional atribuído a ela pelo filho, com importante rendimento simbólico para a afirmação da luta negra no Brasil. De tal forma que comprovações sobre a existência ou não da personagem serão sempre redutoras em face aos efeitos políticos mobilizadores desta última.

Reproduzimos a seguir o pequeno trecho que Gama dedica à mãe na carta autobiográfica, origem das suplementações posteriores, que desembocam com grande vigor e sugestão em Um defeito de cor:

Sou filho natural de uma negra, africana livre, da Costa Mina, (Nagô de Nação) de nome Luíza Mahin, pagã, que sempre recusou o batismo e a doutrina cristã.

Minha mãe era baixa de estatura, magra, bonita, a cor era de um preto retinto e sem lustro, tinha os dentes

\footnotetext{
${ }^{4}$ Ver LIMA. Desvendando Luiza Mahin.

${ }^{5}$ Ver, por exemplo, LUÍSA Mahin.

${ }^{6}$ Ver revisão bibliográfica de Dulcilei da Conceição Lima em Desvendando Luiza Mahin, p. 39-47.
} 
alvíssimos como a neve, era muito altiva, geniosa, insofrida e vingativa.

Dava-se ao comércio - era quitandeira, muito laboriosa, e mais de uma vez, na Bahia, foi presa como suspeita de envolver-se em planos de insurreições de escravos, que não tiveram efeito.

Era dotada de atividade. Em 1837, depois da Revolução do dr. Sabino, na Bahia, veio ela ao Rio de Janeiro, e nunca mais voltou. Procurei-a em 1847, em 1856, em 1861, na Corte, sem que a pudesse encontrar. Em 1862 , soube, por uns pretos minas, que conheciam-na e que deram-me sinais certos que ela, acompanhada com malungos desordeiros, em uma 'casa de dar fortuna', em 1838, fora posta em prisão; e que tanto ela como os seus companheiros desapareceram. Em opinião dos meus informantes que esses 'amotinados' fossem mandados para fora pelo governo, que, nesse tempo, tratava rigorosamente os africanos livres, tidos como provocadores.

Nada mais pude alcançar a respeito dela. ${ }^{7}$

É imperioso notar como, além da duplicação nominal, as características sediciosas do retrato materno são como espelho do... filho. ${ }^{8}$

No romance de Gonçalves, o célebre abolicionista vem à luz chamado Omotunde Adeleke Danbiran, ${ }^{9}$ fruto de relacionamento de Kehinde com um comerciante português. Este acaba por vender o filho a mercadores de escravos, traindo ignominiosamente a relação que haviam construído. ${ }^{10}$ Trauma que motiva o longo relato de Kehinde, o reencontro impossível com Omotunde/Luiz é duplicação dos óbices e desvios fundadores do povoamento negro no Brasil. Móvel que Gonçalves se dispõe a formalizar, trata-se de atitude artística grandiosa e interventiva, ela mesma figurada no prólogo de Um defeito de cor: é a autora que

\footnotetext{
${ }^{7}$ GAMA. Carta a Lúcio de Mendonça, p. 199-204 apud LIMA. Desvendando Luiza Mahin, p. 142-143.

${ }^{8}$ FERREIRA. Luiz Gama por Luiz Gama, p. 304; AZEVEDO. Orfeu de carapinha, p. 69 apud LIMA. Desvendando Luiza Mahin, p. 40.

${ }^{9}$ GONÇALVES. Um defeito de cor, p. 404.

${ }^{10}$ GONÇALVES. Um defeito de cor, p. 630-634.
} 
"acha" a longa missiva de Kehinde/Luísa, "assumindo" - já no começo do século XXI - a tarefa compiladora e transcritora. ${ }^{11}$

Kehinde perderá mãe e irmão mais velho no começo arrebatadoramente brutal do relato. A avó de Kehinde expressara culto divergente do permitido no reinado de Daomé, mudando-se com a família de sua então capital - Abomé (ou Abomey) - para Savalu. Mas é "descoberta" por guerreiros que temem seu culto ao vodun Dan.

Os guerreiros conversavam depressa e aos gritos, decerto resolvendo o que fazer, enquanto eu e a Taiwo ${ }^{12}$ nos demos as mãos, sem entendermos direito o que estava acontecendo. A minha avó se atirou ao chão diante deles, implorando que fossem embora, que levassem tudo o que quisessem levar, que Olorum os acompanhasse. Eles não a ouviam e falavam de feitiços, de pragas e de Agontimé. Como se já não houvesse sombra sob o iroco, uma outra [...] ainda mais escura e no formato de asas de um grande pássaro voou sobre a cabeça da minha avó. Eu já tinha ouvido falar daquele tipo de pássaro, era uma das ìyámis, uma das sete mulheres-pássaro que quase sempre carregam más notícias. ${ }^{13}$

Agontimé, conforme indicado em nota explicativa por Gonçalves, é "uma das rainhas do Daomé, acusada de feitiçaria pelo rei Adandozan (regência: 1797-1818) ${ }^{14}$ e vendida como escrava. Uma das principais sacerdotisas do culto a Dan, a serpente sagrada, e a Elegbatá, o orixá da varíola e das pestes". ${ }^{15}$ Resultado da disputa pelo trono de Daomé, a maldição atribuída a Agontimé acaba por atingir a família de Kehinde

${ }^{11}$ GONÇALVES. Um defeito de cor, p. 9-17. No romance de Gonçalves, grafa-se "Luísa", ao invés do original com “ $z$ " utilizado por Luiz Gama. A diferença, embora mínima, é estratégica, como notou Fabiana Carneiro da Silva, posto que reafirma uma relação de "similaridade não idêntica" entre o romance e sua matéria (SILVA. Maternidade negra em Um defeito de cor, p. 92). Voltaremos com vagar a esse ponto. ${ }^{12}$ Seguindo a cosmologia iorubá, nomeia-se o primeiro gêmeo vindo à luz como Taiwo. O segundo é Kehinde (OGUNYEMI. Africa Wo/Man Palava, p. 74). São ibêjis (gêmeos) (GONÇALVES. Um defeito de cor, p. 19, nota).

${ }^{13}$ GONÇALVES. Um defeito de cor, p. 22, grifo da autora.

${ }^{14}$ FERRETI. Repensando o sincretismo, p. 117.

${ }^{15}$ GONÇALVES. Um defeito de cor, p. 22, nota. 
por meio de sua avó. ${ }^{16}$ Com a mãe e o irmão mais velho assassinados, Kehinde parte para o litoral, em Uidá, com a avó e a irmã gêmea. Sofrerá, por fim, revés definitivo. Em cenas que reconstroem o vultoso mercado de escravos do golfo do Benim, já no século XIX, a narradora é capturada por traficantes. Sobrevive ao "tumbeiro", mas chega ao continente americano sem os familiares, vítimas da travessia e seu horror.

Em uma reconstrução à altura de suas exigências, reconstrução que contamos rara em toda literatura brasileira - há, com efeito, os versos de Castro Alves ${ }^{17}$ e, antes deles, o romance pioneiro de Maria Firmina dos Reis ${ }^{18}$-, é com sentidos colapsados que o leitor se aproxima da experiência (apenas, contudo, literária).

A comida começou a apodrecer por todo o chão do navio, porque muitos, e eu também, já não tínhamos mais apetite, e ao cheiro dela se juntava o cheiro de xixi, de merda, de sangue, de vômito e de pus. Acho que todos nós já queríamos morrer no dia em que abriram a portinhola e mandaram que nos preparássemos para sair. Foi preciso repetir a ordem novamente, e novamente, porque faltava ânimo, faltava força [...]. Disseram que iam nos levar para tomar banho, beber água e ficar um pouco ao sol. Foi o sol que me animou a sair, e também fez com que nossos olhos ardessem ao deixarmos o porão, a ponto de não conseguirmos abri-los, andando e caindo uns por cima dos outros [...] não só por causa da fraqueza, mas porque as pernas pareciam ter se desacostumado do peso do corpo, sempre deitado. ${ }^{19}$

Chegando ao Brasil, batiza-se com o nome de Luísa, na impossibilidade de seguir expressando o original "pagão". ${ }^{20}$ Será, doravante, Luísa Gama, em adoção do sobrenome de seu primeiro senhor,

${ }^{16}$ GONÇALVES. Um defeito de cor, p. 131, 596, 782-785.

${ }^{17}$ ALVES. O navio negreiro.

${ }^{18}$ REIS. Úrsula. Para uma análise deste que é o primeiro romance afro-brasileiro publicado - embora, e de modo sintomático, ausente das principais historiografias da literatura nacional -, ver DUARTE. Maria Firmina dos Reis e os primórdios da ficção afro-brasileira.

${ }^{19}$ GONÇALVES. Um defeito de cor, p. 56-57.

${ }^{20}$ GONÇALVES. Um defeito de cor, p. 72-73. 
um fazendeiro de Itaparica (BA), senhor de engenho em decadência, cujas terras seriam logo vendidas. ${ }^{21}$ Pela idade, é designada como companhia para a filha do senhor, o que permite à protagonista aprender a ler e a escrever, durante as aulas de sua sinhazinha com um "muçurumim" (escravo mulçumano) chamado Fatumbi. Na fazenda, contudo, à medida que cresce, de pouco lhe adianta a indicação para serviços domésticos e, por consequência, para a "senzala pequena", dos negros da casa-grande: é exposta à barbárie da posse escrava, do estupro à castração de um companheiro negro que pretendia livrá-la da gana de seu algoz. ${ }^{22}$

Mas se Gonçalves, em seu ímpeto de figuração histórica, não se exime de recolher as mais violentas realizações dos regimes colonial e imperial no Brasil, individualizadas na trajetória da protagonista, também a sobrevivência terá marcante papel na narrativa. A formalização de núcleos saudáveis, ademais, transplantados para o cativeiro e mesmo neste cultivados por meio tanto da socialização étnica quanto da religiosidade de origem, perfaz a mais impressionante contribuição da escritora. Com efeito, Kehinde logo encontra uma conterrânea da nação jeje, povo a que pertence. Mesmo impedida de falar livremente o iorubá e o eve-fon, suas línguas natais ${ }^{23}$, descobre em Nega Florinda um guia espiritual e sucedâneo de sua avó.

Ela também era jeje, capturada em Ardra mais de sessenta anos antes, vivendo como liberta havia mais de trinta. No Daomé, tinha chegado a ser vodu-no [sacerdotisa no culto a Dan], como a minha avó antes de ser expulsa da corte de Abomé. [...] No Brasil, o culto aos orixás era forte demais até para o grande poder que os voduns possuíam. Ela [...] disse que eu poderia me valer dos orixás para cultuar alguns voduns, porque, na Bahia, Mawu, Khebiosô, Legba, Anyi-ewo, Loko, Hoho, Saponan e Wu eram cultuados como Olorum, Xangô, Elegbá, Oxum, Iroco, Ibêjis, Xaponã e Olokum. [...] [O]s orixás já tinham tomado conta das cabeças dos pretos e o culto deles vinha de muito tempo, praticado por quase todos os africanos

${ }^{21}$ GONÇALVES. Um defeito de cor, p. 185.

${ }^{22}$ GONÇALVES. Um defeito de cor, p. 166-172.

${ }^{23}$ GONÇALVES. Um defeito de cor, p. 77. 
que [...] iam parar naquelas terras. Nossos voduns nunca teriam força para ganhar um pouco de espaço ou atenção, e para eles estava destinado um lugar não muito longe dali, do qual, por enquanto, ela nada podia falar. A Nega Florinda foi embora prometendo me ajudar, primeiro com o pingente da Taiwo, depois com a estátua dos Ibêjis, as maiores urgências. ${ }^{24}$

Apesar do culto aos orixás ser majoritário pela preponderância de nagôs e iorubás na região, ${ }^{25}$ e sem prejuízo do sincretismo que se formara a partir da diversidade étnica africana em solo brasileiro, Kehinde se reaproximará de sua nação: os “jeje-maís” ou "minas-jejes". ${ }^{26}$ Guardará seu culto como os demais companheiros de cativeiro, escondendo em buracos na senzala as esculturas e imagens: "descobri como os pretos guardavam os seus santos, escondidos dos olhos dos brancos, e que todas aquelas paredes já deviam estar apoiadas em quase nada". ${ }^{27}$

E por vicissitudes que viriam a confirmar o que a personagem sente como predestinação e que, na prática, derivam de sua capacidade e formação intelectuais, permitindo a Kehinde um futuro mais lato e ágil - desde a oportunidade das aulas junto à sinhazinha, ao aprendizado do inglês quando trabalhara "alugada" na casa de britânicos, já na capital baiana ${ }^{28}$-, a narradora conseguirá aportar em São Luís (MA), para viver seis meses na Casa das Minas, templo histórico e tombado do povo jeje no Brasil (cuja fundação remete à primeira metade do século XIX ${ }^{29}$ ).

No relato a Omotunde, a chance de reafirmar a comum ancestralidade, retomando sentidos que vira perder com o sequestro do filho ainda criança:

Tenho a impressão de que você não sabe muitas coisas sobre voduns, o que não é bom, porque poderia ter se valido da proteção deles. Os da nossa família são muito

\footnotetext{
${ }^{24}$ GONÇALVES. Um defeito de cor, p. 83-84, grifo da autora.

${ }^{25}$ GONÇALVES. Um defeito de cor, p. 502.

${ }^{26}$ São essas as formas empregadas por Gonçalves em seu romance para designar a nação jeje mahi (ver GONÇALVES. Um defeito de cor, p. 133, 498, 502).

${ }^{27}$ GONÇALVES. Um defeito de cor, p. 90.

${ }^{28}$ GONÇALVES. Um defeito de cor, p. 213, 227.

${ }^{29}$ FERRETTI. Querebentã de Zomadônu, p. 54.
} 
fortes. Portanto, espero que ainda não seja tarde, e peço um pouco de paciência para contar o que sei e posso. ${ }^{30}$

Kehinde passará então a reconstituir o culto na Casa das Minas, em que fora iniciada por Maria Mineira Naê, a rainha Agontimé do Daomé, "redescoberta" no Brasil, para onde viera vendida ${ }^{31}$. Apesar de longo, vale a pena transcrever o seguinte trecho do livro, por ser representativo da formalização geral de sua fatura:

A noche Naê era a gaiacu, a mãe e dona da Casa, e abaixo dela havia os ogãs, e entre eles, os tocadores de tambor, que são muito importantes para o culto. [...] [A] inda havia uma gantó, ou ferreira, que tocava um instrumento de ferro chamado gan e era acompanhada por mais quatro ou cinco mulheres que tocavam instrumentos feitos de pequenas cabaças vestidas com contas coloridas. Ekedi é o feminino de ogã, e são elas as que mais trabalham na arrumação do barracão, das roupas e das cerimônias, e na Casa das Minas as ekedis eram as próprias vodúnsis. Eu ajudava no que me pediam e aprendi um pouco de tudo [...]. Durante a estada, também reaprendi a falar eve-fon, a língua utilizada em todos os cultos e também no dia-a-dia. [...] O barracão onde são realizados os cultos tem o nome de $k w e$, e dentro dele ficam os sabajis, os quartos sagrados que guardam os kpos [potes] com assentamento dos voduns [...]. Zomadonu, o vodum da noche Naê e chefe da Casa,

${ }^{30}$ GONÇALVES. Um defeito de cor, p. 599.

${ }^{31}$ Para mais detalhes a respeito de Nã Agontimé, personagem histórica evocada pelo livro de Gonçalves, é preciso consultar Querebentã de Zomadônu, de Sérgio Ferreti. E também do mesmo autor Repensando o sincretismo, em que o estudioso recupera tese de Pierre Verger, em "Uma rainha africana mãe de santo em São Luís", sobre a provável fundação da Casa das Minas pela rainha daomeana, "viúva do rei Agonglô e mãe do futuro rei Ghezo [regência: 1818-1858]" (FERRETTI. Repensando o sincretismo, p. 117). Em contraste, todavia, com a forma escolhida por Gonçalves em seu romance, a memória oral da Casa maranhense registra sua fundadora como Maria Jesuína. A escolha de Gonçalves curiosamente replica o samba-enredo da Beija-Flor no Carnaval de 2001, denominado "Agotimé Maria Mineira Naê" (FERRETTI. Beija-flor e a Casa das Minas). Vale frisar que a Casa das Minas talvez seja "o único lugar fora da África em que são cultuados voduns da família real de Abomey" (FERRETI. Querebentã de Zomadônu, p. 20). 
tinha proibido o culto a Legba, depois de tê-lo acusado de ser o responsável pela expulsão das vodúnsis do Daomé. A noche Naê [...] obedecia ao seu vodum, sendo, porém, autorizada a oferecer um cântico a Legba no início de cada culto, para que ele não atrapalhasse. ${ }^{32}$

Gonçalves versa frontalmente sobre a firmeza e profundidade dos laços sociais trazidos pelas nações africanas transplantadas. Em registro artístico e literário, tal abordagem - que constitui o valor original do romance - complementa, por exemplo, as manifestas limitações de uma das, ainda hoje, mais abrangentes radiografias sociológicas sobre a composição negra no Brasil, a tese $A$ integração do negro na sociedade de classes, de Florestan Fernandes. Neste que é um dos primeiros grandes estudos brasileiros a combater de forma sistemática o mito da "democracia racial" no país, ${ }^{33}$ o sociólogo trata com detalhes do movimento social negro na primeira metade do século XX, dissertando, inclusive, sobre a importância contemporânea de Luiz Gama ${ }^{34}$, mas falha fragorosamente em ver além de tais movimentos e da sempre baixa adesão que lograram junto às massas negras urbanas. Aferindo a importância dessas associações civis - entre as quais a Frente Negra Brasileira e o grupo do Clarim da Alvorada (pujante órgão da imprensa negra paulistana, publicado entre 1924 e 1932) - e também o fracasso relativo de sua influência, deixa de versar sobre fenômenos de sociabilidade cotidianos, verdadeiros núcleos salutares à sobrevivência e integração negras, como as crenças e a espiritualidade transplantadas e mantidas. Pela desimportância com que figuram no quadro sociológico definido - a

${ }^{32}$ GONÇALVES. Um defeito de cor, p. 600-601, grifos da autora.

${ }^{33}$ FERNANDES. A integração do negro na sociedade de classes, v. 1, p. 304-327.

${ }^{34}$ Vejamos passagem em que há referência direta ao herói da Abolição recuperado pelos movimentos sociais negros: "Ao desmascaramento na ordem moral, correspondiam a laboriosa reconstrução do papel histórico desempenhado pelo 'negro' no passado da sociedade brasileira e a exigência de verdadeiro respeito mútuo nas relações raciais. Assim, datas como o 28 de Setembro e o 13 de Maio adquiriram nova significação; pessoas como Patrocínio, Luís Gama (sic), Rebouças, e tantos outros, receberam um autêntico preito engrandecedor; e os fundamentos axiológicos da ordem social competitiva e democrática sofreram uma reinterpretação realmente íntegra e puritana" (FERNANDES. A integração do negro na sociedade de classes, v. 2, p. 127, grifos nossos). É no mesmo flanco simbólico dessa luta que Ana Maria Gonçalves almeja posicionar-se. 
despeito das proporções monumentais do estudo, que abrange desde a década de 1880 até os anos 1960 -, tais fenômenos acabam tragados seja pelas consequências da "exposição prolongada e inelutável a condições crônicas de anomia", ${ }^{35}$ seja pelas tendências centrífugas e seculares de urbanização com veto à “preservação de 'mores' afro-brasileiros, que poderiam garantir a transformação da 'população negra' numa minoria racial integrada e autônoma". ${ }^{36}$

A heroica integração de comunidades em centros como a Casa das Minas - referências que ecoam para além de suas sedes geográficas - e a persistência dos laços apesar das condições precaríssimas de subsistência não têm vez no retrato sociológico sombrio que reputava a desorganização societária crônica e seus efeitos deletérios. O mais saliente destes sendo a impossibilidade das populações negras se "equiparem" com conhecimentos e comportamentos indispensáveis à incipiente sociabilidade competitiva (cuja demanda por secularização dos estilos de vida era também emulada pelos movimentos negros organizados, os quais divisavam aí, de modo realista, o caminho para a Segunda Abolição). ${ }^{37}$

Se Kehinde ascende na escala social e escapa à média de seus consortes - média essa aferida por Florestan Fernandes a partir de 1880, mas remetida, outrossim, às condições contextuais das décadas anteriores -, certamente é pelo talento na assimilação da cultura letrada e do tipo de comportamento a ela vinculado. ${ }^{38}$ Tal encaminhamento figurativo está em linha, portanto, com a incorporação de técnicas sociais competitivas, cuja importância o sociólogo paulistano divisara sem eximir-se de avaliar o fenômeno, quando existente, como ainda circunscrito à "ascensão social parcelada", apenas individual, e, por isso mesmo, "consagrada tradicionalmente" (no que devia à manutenção do status quo em tal fase de desagregação do regime servil). ${ }^{39}$ Mas a sobrevivência de Kehinde

\footnotetext{
${ }^{35}$ FERNANDES. A integração do negro na sociedade de classes, v. 1, p. 277.

${ }^{36}$ FERNANDES. A integração do negro na sociedade de classes, v. 1, p. 120, grifo do autor.

${ }^{37}$ FERNANDES. A integração do negro na sociedade de classes, v. 2, p. 64 passim.

${ }_{38}$ Nesse ponto, é central o contato constante com os escravos mulçumanos (GONÇALVES. Um defeito de cor, p. 455-568), cuja crença em Meca e a leitura sagrada do Alcorão são trazidas do continente africano. Isso porque seu letramento é outro ponto de partida para a composição na sociedade brasileira.

${ }^{39}$ FERNANDES. A integração do negro na sociedade de classes, v. 1, p. 320-321.
} 
não depende menos de seu "paganismo", embora tenha que disfarçá-lo, de modo compulsório, a todo tempo. A força mais elementar que move a narradora almeja a reunião definitiva com a família massacrada e, depois, dispersa (com a cruel venda de Omotunde). Por isso, de modo paralelo ao sucesso das empreitadas comerciais que banca, ${ }^{40}$ há sempre a busca pela manutenção do elo de origem, o que integra sua personalidade, apesar dos muitos exílios.

No navio negreiro, a separação é a oportunidade extremada de afirmação do vínculo: potencialmente perdido, encontrará na sobrevivência de Kehinde razão de continuidade.

Algumas horas depois de terem levado a Taiwo [a irmã, morta, havia sido jogada ao mar], como se estivesse apenas esperando que ela partisse [...], a minha avó disse que estava [...] fraca e cansada, que perdia a força e a coragem longe dos seus voduns [...]. Durante dois dias ela me falou sobre [...] a importância de cultuar e respeitar os nossos antepassados. [...] [M] esmo que não fosse através dos voduns, ela disse para eu nunca me esquecer da nossa África, da nossa mãe, de Nanã, de Xangô, dos Ibêjis, de Oxum, do poder dos pássaros e das plantas, da obediência e respeito aos mais velhos, dos cultos e agradecimentos. ${ }^{41}$

Nesse sentido, a ficcionalização histórica erigida por Ana Maria Gonçalves vai além dos quadros documentais disponibilizados em profusão por Fernandes e outros estudiosos da sociologia crítica brasileira $^{42}$, para apropriar-se da "memória e experiência coletiva" que, segundo indica com percuciência Fabiana Carneiro da Silva,

\footnotetext{
${ }^{40} \mathrm{O}$ êxito comercial começa com uma banca móvel de cookies - receita aprendida na casa britânica em que trabalhara - e avança, ainda em São Salvador, para uma padaria; ao final, a grande senhora, estabelecida em Lagos, envia os filhos mais jovens para estudar em Paris (GONÇALVES, Um defeito de cor, p. 914-916). Sendo em tudo pioneira, a personagem tentará o último retorno ao Brasil: país de sua afirmação como sujeito da história, mas também de sua maior derrota.

${ }^{41}$ GONÇALVES. Um defeito de cor, p. 60-61.

${ }^{42}$ Cf., por exemplo, as pesquisas pioneiras de Octávio Ianni (As metamorfoses do escravo) e Fernando Henrique Cardoso (Capitalismo e escravidão no Brasil meridional).
} 
"sobreviveram aos mais violentos mecanismos de ocultamento e permaneceram vivas". ${ }^{43}$

O longo descrever das tradições silenciadas - sempre ativas, não obstante -, a incorporação textual de léxico iorubá, eve-fon, hauçá ${ }^{4}$ e quicongo ${ }^{45}$, procedimentos associados à formação da narradora e protagonista de Um defeito de cor, desvelam aos leitores a opção narrativa pela permanência da superação. Tentativa de mímesis da luta negra no Brasil, impõem outra agenda poética à literatura brasileira, sustentada por pesquisa exaustiva de culturas originárias.

\section{Limites formais}

Todavia, se com Ana Maria Gonçalves escapamos, assim, de limitar a experiência afro-brasileira à marginalidade e desagregação socioeconômicas - e há indícios desse viés de redução fatalista até mesmo, como vimos, na acurada tese de Florestan Fernandes ${ }^{46}$, , seria

${ }^{43}$ SILVA. Maternidade negra em Um defeito de cor, p. 70. Um curioso mea culpa, acionado em determinado momento da tese de Florestan Fernandes, recupera a importância dos "traços culturais transplantados" para a adaptação das populações afrobrasileiras, mas é, a nosso ver, de todo insuficiente quando contraposto à orientação geral do estudo: "[N]ão ignoramos a influência dinâmica de traços culturais transplantados da África e reelaborados no Brasil, embora isso possa parecer pouco evidente na apresentação dos resultados de nossa investigação. Julgamos que M. J. Herskovits tinha razão quando ressaltava a conotação etnocêntrica das reconstruções ou das explicações que negam o 'passado histórico do negro' e sua importância nos processos adaptativos ou integrativos ocorridos nas Américas. [...] [A]s questões suscitadas pela plasticidade do comportamento humano diante de condições anômicas de existência podem ser focalizadas na literatura etnossociológica brasileira [...], que nos mostra como um povo tribal enfrenta os efeitos da desorganização permanente do sistema sociocultural" (FERNANDES. A integração do negro na sociedade de classes, v. 1, p. 425-426).

${ }^{44}$ GONÇALVES, Um defeito de cor, p. 308, 515.

${ }^{45}$ GONÇALVES, Um defeito de cor, p. 501, 690-693.

${ }^{46}$ Muito comum e de efeitos devastadores para a imagem e autoimagem do povo negro no Brasil, tal linha de entendimento fatalista, que pode, como no caso da tese de Fernandes, ser balanceada pelo destaque concomitante do poder negro de agência, sedimenta-se também de maneira extremada e não apenas em registro científico/ sociológico, mas igualmente em elaborações artísticas e literárias. Na literatura de autoria negra, por exemplo, obra de maior destaque nas últimas décadas, o romance Cidade de Deus, de Paulo Lins, erige figuração estritamente marginal e pré-política da 
insuficiente não ler Um defeito de cor também segundo as escolhas formais que impedem sua plena realização.

Embora quebre a rígida homogeneidade branca e masculina do perfil autoral cara ao campo literário brasileiro, Gonçalves opta por conformar tradicionalmente sua obra. Não obstante o ponto de vista narrativo e sua sólida matéria - originada em boa parte na pesquisa exaustiva - serem absolutamente extemporâneos ao grosso de nossa produção, e sustentarem a relevante originalidade do romance, estão dispostos de modo conservador. A linearidade absoluta da narrativa aponta para o conteúdo tornado imóvel, refém da própria magnitude, e a mão condutora acanha-se seguindo lógica que proíbe qualquer distorção, mesmo as meramente figurativas. No trecho destacado mais acima, quando se trata de narrar a estrutura litúrgica da Casa das Minas, a limitação formal é saliente: Gonçalves, nutrindo completo respeito pelo assunto abordado, não é capaz de avançar seu trabalho de ficcionalização e elaboração artística um passo além da descrição reverencial. Se isso é particularmente sensível sobre o conteúdo religioso estrito, não é menos determinante nos demais momentos. A ausência de alternativas formais à narração linear, em livro tão volumoso, acaba por gerar repetições maçantes, cujo trabalho de reiteração de componentes da trama constrange o romance a sua invariância.

A matéria, forte, basta a si mesma, até o ponto em que, nos piores lances, descamba para o didatismo exacerbado, algo escolar, que é construído como componente do tom paternal de um relato de mãe para filho. A premência da empresa e o compromisso político de Gonçalves em levá-la a cabo engessam, dessa forma, as soluções. Sem "desconfiança" crítica sobre o que se narra, tentando mesmo ser o mais fiel possível à importância da história, desprende-se efeito embaraçoso: o "enxerto" por vezes artificial de acontecimentos, personagens e costumes históricos - fatos e o próprio movimento da cultura têm seu sentido humano esterilizado e transformam-se em curiosidades bem-intencionadas. Nesse sentido, o tratamento dissolutivo, cômico ou até mesmo cínico da matéria histórica pode ser - em contradição apenas aparente - mais "sério" do que o tratamento descritivo e linear. No primeiro, não há reverência à

população negra carioca (ver LINS. Cidade de Deus). Uma comparação entre os livros de Lins e Gonçalves é, nesse sentido, programa crítico de extrema produtividade, que infelizmente deixamos apenas indicado nesta ocasião. 
realidade ou a compromissos pétreos que suplante a liberdade relativa da criação literária, seus voos mais ou menos desimpedidos.

Como notou Fabiana Carneiro da Silva, no nível mais estrito da linguagem, a longa epístola figurada em Um defeito de cor apresenta uma inverossímil ausência de "perturbação (hiatos, elipses, hipérboles) [...] mesmo quando descritos os episódios mais violentos" ${ }^{47}$ da vida da narradora. Entre a vivência subjetiva de Kehinde e o "empenho de reescrever os significativos episódios históricos, sobretudo do Brasil, que ocorreram no período compreendido nessa trajetória individual" 48 há, segundo Silva, marcante falha de articulação, que fragiliza a potência particular da obra - tal qual viemos descrevendo -, qual seja: sua liberdade (possível apenas ao registro da ficção) de reelaborar a "história pretensamente nacional, tendo como filtro o âmbito dos interesses, percepções [...] e subjetividades daquelas que ou foram excluídas ou mantiveram-se oprimidas, às margens das historiografias oficiais". ${ }^{49}$ Os "momentos de força da obra", também segundo a percepção crítica de Silva, seriam aqueles em que "a subjetividade de Luísa opera como lente para seleção e narração dos fatos históricos a que temos acesso". ${ }^{50}$ Sofrendo a concorrência quase permanente de uma aridez estilística, são tais momentos ${ }^{51}$ que se aproximam com maior alcance da memorialística afro-brasileira, sobretudo oral, cujos traços culturais ainda pouco sistematizados pelas ciências humanas o romance tem o mérito de disseminar.

As consequências dessa limitação de alternativas formais estão, portanto, paradoxalmente ligadas a um distanciamento descritivo próximo à dicção historiográfica ou "científica", que procura dar conta, de maneira objetiva, da cultura (e conhecemos o regramento textual desse campo do conhecimento: "doctrina primus, stilus ultimus"52). Logo o

\footnotetext{
${ }^{47}$ SILVA. Maternidade negra em Um defeito de cor, p. 117.

${ }^{48}$ SILVA. Maternidade negra em Um defeito de cor, p. 116.

${ }^{49}$ SILVA. Maternidade negra em Um defeito de cor, p. 116.

${ }^{50}$ SILVA. Maternidade negra em Um defeito de cor, p. 117.

${ }^{51}$ Podemos indicar como exemplo a narração da experiência da viagem no navio negreiro, segundo trecho que destacamos no início do artigo.

${ }^{52}$ Em oposição ao "regramento" de tipo literário - "stilus primus, doctrina ultimus" -, que tende a indicar a insuficiência do discurso científico na representação da realidade (WAIZBORT. As aventuras de Georg Simmel, p. 61). Nesse jogo diferenciador entre campos de produção cultural, são relevantes as restrições que - em período heroico
} 
âmbito logocêntrico a que o romance quer contrastar com a mobilização de repertório simbólico ainda pouco "registrado". Vejamos trecho em que, dirigindo-se ao filho, a narradora reflete sobre a questão de maneira metaficcional (e também meta-histórica ${ }^{53}$ ):

[O]s africanos não gostam de pôr histórias no papel, o branco é que gosta. Você pode dizer que estou fazendo isso agora, deixando tudo escrito para você, mas esta é uma história que eu teria te contado aos poucos, noite após noite, até que você dormisse. E só faço assim, por escrito, porque sei que já não tenho mais esse tempo. Já não tenho mais quase tempo algum, a não ser o que já passou e que eu gostaria de te deixar como herança. ${ }^{54}$

A autoconsciência sobre a empresa poética que a autora banca, visível, como indicamos, desde o prólogo ao romance, em que Ana Maria Gonçalves apresenta-se como personagem compiladora dos manuscritos ditados por Kehinde, não é, entretanto, recurso suficiente de relativização e complexificação da narrativa. Isso porque o expediente permanece como mero artifício temático e não influencia o nível mais elementar da linguagem, mantida em sucessão estanque e com poucos ruídos - isto é, diversa do dinamismo, vivacidade, bem como das inflexões lacunares e falhas reminiscentes característicos da tradição de transmissões orais ${ }^{55}$

de fundação (melhor seria dizer, autonomização) da disciplina sociológica no Brasil Florestan Fernandes nutria relativamente à forma ensaística empregada por intérpretes da geração anterior, como, por exemplo, Gilberto Freyre. O sociólogo ligava tal gênero de exposição, no que tinha de fronteiriço com a forma literária, a "uma concepção estamental do mundo", pouco afeita aos rigores da nova disciplina, bem como ao modo radical de seu exercício, que pressuporia uma "democratização da cultura" (FERNANDES. A sociologia numa era de revolução social, p. 226, 230).

${ }^{53}$ Sobre esse ponto, ver DUARTE. Na cartografia do romance afro-brasileiro, $\mathrm{Um}$ defeito de cor, de Ana Maria Gonçalves. O crítico define a obra de Gonçalves como "metaficção historiográfica". Tal avaliação crítica problematiza o enquadramento do livro como "romance histórico". Infelizmente, não poderemos desenvolver a questão nesta oportunidade, restando-nos indicar a ponderada leitura de Fabiana Carneiro da Silva, que reconstitui o conceito desse subgênero à luz de Um defeito de cor (SILVA. Maternidade negra em Um defeito de cor, p. 57-71).

${ }^{54}$ GONÇALVES. Um defeito de cor, p. 617.

${ }^{55} \mathrm{Na}$ importância medular que tem para a cultura afro-brasileira (FERRETI. Querebentã de Zomadônu, p. 41). 
que o livro identifica a si. Há apenas, no início da obra, o mencionado deslocamento temporal - um "avanço" até o século XXI -, em que a autora-personagem chega mesmo a indicar edições e invenções sobre trechos perdidos e ilegíveis do que tem à mão. ${ }^{56}$ Mas a audácia reflexiva não chega a intervir no retilíneo texto subsequente, que se desenrola sem atropelos temporais ou emersões de perspectivas conflitantes, que se concretizem a ponto de fissurar ou desestabilizar a univocidade incômoda da obra. O tom é mantido até as páginas finais, em que a situação de narração - o navio e a tentativa de último regresso ao Brasil - é revelada.

\section{Considerações finais}

A despeito de tais indicações, a crítica é menor se bem vista a importância incontornável de Um defeito de cor para os campos de produção simbólica desse início de século no Brasil. "Acerto de contas" com a história da participação negra no país, o que assume como memória ficcional é tudo aquilo que as mãos brancas e masculinas - não mais "versadas", como quer a sabotagem racista: simplesmente privilegiadas - registraram a seu modo implicado. Sendo possível identificar numa das cenas em que a narradora relata a busca por seu filho perdido, no Rio de Janeiro dos anos 1840, a inscrição do motivo central ao romance, figurado no ímpeto narrativo de Kehinde: resposta massiva que se constrói em alerta às redutoras hegemonias da história.

Será que você gosta de ler? O que será que você gosta de comer? Será que encontrou uma boa esposa? Teve filhos? Quantos? São muitas as minhas perguntas e sei que ficarão sem resposta. E como sei que isto é ruim, tento me lembrar de cada detalhe importante da minha vida, para responder a todas as dúvidas que você pode nem saber que tem. Sabe que tenho realizado um grande sonho? Não exatamente como o sonhei, mas já é alguma coisa, porque naqueles dias em São Sebastião eu pensava muito em quantas coisas teria para te contar quando nos encontrássemos, em todos os lugares a que eu queria te levar, nas pessoas a quem queria te apresentar. De certo modo é o que faço, embora quase

${ }^{56}$ GONÇALVES. Um defeito de cor, p. 16-17. 
nada do que estou falando faça parte da nossa memória em comum, como eu gostaria que fosse..$^{57}$

O que por forças históricas ainda se nega à memória brasileira e a sua identidade plural é retomado em Um defeito de cor, que descomprime a experiência negra dos patamares rebaixados a que sempre esteve submetida.

\section{Referências}

ALVES, Antônio de Castro. O navio negreiro. In: Os escravos. São Paulo: L\&PM, 1997. p. 92-101.

AZEVEDO, Elciene. Orfeu de carapinha: a trajetória de Luiz Gama na imperial cidade de São Paulo. Campinas: Unicamp, 1999 apud LIMA, Dulcilei da Conceição. Desvendando Luiza Mahin: um mito libertário no cerne do feminismo negro. 2011. 161 f. Dissertação (Mestrado em Educação, Arte e História da Cultura) - Universidade Presbiteriana Mackenzie, São Paulo, 2011. Disponível em: <http://tede.mackenzie.br/ jspui/bitstream/tede/1821/1/Dulcilei\%20da\%20Conceicao\%20Lima. pdf $>$. Acesso em: 12 jun. 2018.

CARDOSO, Fernando Henrique. Capitalismo e escravidão no Brasil meridional: o negro na sociedade escravocrata do Rio Grande do Sul. 4. ed. Rio de Janeiro: Paz e Terra, 1997.

DALCASTAGNÈ, Regina. Um mapa de ausências. In:

Literatura brasileira contemporânea: um território contestado. Vinhedo: Editora Horizonte; Rio de Janeiro: Editora da UERJ, 2012. p. 147-196.

DUARTE, Eduardo de Assis. Maria Firmina dos Reis e os primórdios da ficção afro-brasileira. IN: REIS, Maria Firmina dos. Úrsula. Florianópolis: Mulheres; Belo Horizonte: PUC Minas, 2004. p. 265-281.

DUARTE, Eduardo de Assis. Na cartografia do romance afro-brasileiro, Um defeito de cor, de Ana Maria Gonçalves. In: TORNQUIST Carmen Susana. et al. (Org.). Leituras da resistência: corpo, violência, poder. Florianópolis: Mulheres, 2009. p. 325-348.

FERNANDES, Florestan. A integração do negro na sociedade de classes. São Paulo: Globo, 2008. v. 2: No limiar de uma nova era.

${ }^{57}$ GONÇALVES. Um defeito de cor, p. 662. 
FERNANDES, Florestan. A integração do negro na sociedade de classes. 5. ed. São Paulo: Globo, 2008. v. 1: O legado da "raça branca".

FERNANDES, Florestan. A sociologia numa era de revolução social. 2. ed. Rio de Janeiro: Zahar, 1976.

FERREIRA, Ligia Fonseca. Luiz Gama por Luiz Gama: carta a Lúcio de Mendonça. Teresa: Revista de literatura brasileira, São Paulo, n. 8-9, dez. 2008. Disponível em: <https://www.revistas.usp.br/teresa/article/ view/116741/114299>. Acesso em: 12. jun. 2018.

FERRETTI, Sérgio. Beija-flor e a Casa das Minas. Comissão Maranhense de Folclore: Boletim On-line, São Luís, n. 18, jan. 2001. Disponível em: $<$ http://www.cmfolclore.ufma.br/arquivos/789439a580ff99114aabae36 63f4971e.pdf $>$. Acesso em: 12 jun. 2018.

FERRETTI, Sérgio. Querebentã de Zomadônu: etnografia da Casa das Minas do Maranhão. 3. ed. Rio de Janeiro: Pallas, 2009.

FERRETTI, Sérgio. Repensando o sincretismo: estudo sobre a Casa das Minas. Prefácio de Reginaldo Prandi. São Paulo: Edusp; São Luís: Fapema, 1995.

GAMA, Luiz. Carta a Lúcio de Mendonça: São Paulo, 25 de julho de 1880. In: FERREIRA, Ligia Fonseca. Com a palavra Luiz Gama: poemas, artigos, cartas, máximas. São Paulo: Imprensa Oficial do Estado, 2011, p. 199-204 apud LIMA, Dulcilei da Conceição. Desvendando Luíza Mahin: um mito libertário no cerne do feminismo negro. 2011. 161 f. Dissertação (Mestrado em Educação, Arte e História da Cultura) - Universidade Presbiteriana Mackenzie, São Paulo, 2011. Disponível em: $<$ http://tede.mackenzie.br/jspui/bitstream/tede/1821/1/Dulcilei\%20 da\%20Conceicao\%20Lima.pdf>. Acesso em: 12 jun. 2018.

GONÇALVES, Ana Maria. Um defeito de cor. 11. ed. Rio de Janeiro: Record, 2015.

IANNI, Octávio. As metamorfoses do escravo: apogeu e crise da escravatura no Brasil Meridional. São Paulo: Difusão Europeia do Livro, 1962.

LIMA, Dulcilei da Conceição. Desvendando Luíza Mahin: um mito libertário no cerne do feminismo negro. 2011. $161 \mathrm{f}$. Dissertação (Mestrado em Educação, Arte e História da Cultura) - Universidade 
Presbiteriana Mackenzie, São Paulo, 2011. Disponível em: <http:// tede.mackenzie.br/jspui/bitstream/tede/1821/1/Dulcilei\%20da $\% 20$ Conceicao\%20Lima.pdf $>$. Acesso em: 12 jun. 2018.

LINS, Paulo. Cidade de Deus. 2. ed. São Paulo: Companhia das Letras, 2002.

LUÍSA Mahin. Fundação Cultura Palmares, Brasília, [2016?]. Disponível em: $<$ http://www.palmares.gov.br/?p=26662>. Acesso em: 12 jun. 2018.

OGUNYEMI, Chikwenye Okonjo. Africa Wo/Man Palava: The Nigerian Novel by Women. Chicago: The University of Chicago Press, 1996.

REIS, Maria Firmina dos. Úrsula. Florianópolis: Mulheres; Belo Horizonte: PUC Minas, 2004.

SILVA, Fabiana Carneiro. Maternidade negra em Um defeito de cor: história, corpo e nacionalismo como questões literárias. 2017. 209 f. Tese (Doutorado em Letras) - Faculdade de Filosofia, Letras e Ciências Humanas, Universidade de São Paulo, São Paulo. 2017. Disponível em: $<$ http://www.teses.usp.br/teses/disponiveis/8/8151/tde-28032018104918/pt-br.php $>$. Acesso em: 14 jun. 2018.

VERGER, Pierre. Uma rainha africana mãe de santo em São Luís. Revista USP, São Paulo, n. 6, jun./ago. 1990, p. 151-158. Disponível em: <http:// www.revistas.usp.br/revusp/article/view/35735/38451>. Acesso em: 12 jun. 2018.

WAIZBORT, Leopoldo. As aventuras de Georg Simmel. 2. ed. São Paulo: Ed. 34, 2006.

Recebido em: 28 de junho de 2018. Aprovado em: 20 de novembro de 2018. 